\title{
A new $M_{D}-M_{L}$ relationship for Mt. Etna earthquakes (Italy)
}

\author{
Tiziana Tuvè ${ }^{\star}$ Salvatore D’Amico, Elisabetta Giampiccolo
}

Istituto Nazionale di Geofisica e Vulcanologia, Sezione di Catania, Osservatorio Etneo, Catania, Italy

\author{
Article history \\ Received July 16, 2015; accepted November 6, 2015. \\ Subject classification: \\ Mt. Etna, Duration magnitude, Local magnitude, General orthogonal regression.
}

\begin{abstract}
A homogenous database of magnitude observations is a basic requirement for seismic hazard estimation and other seismic studies. Unfortunately, the magnitude reported in the seismic catalogue of Mt. Etna is not homogenous. Only the duration magnitude $\left(M_{D}\right)$ is available up to 2005 , while since then the more stable local magnitude $\left(M_{L}\right)$ has also been calculated. To have a uniform dataset, earthquake data recorded at Mt. Etna during the period 2005-2014 were used to derive a new relationship between local and duration magnitude, by applying the General Orthogonal Regression (GOR), which is an alternative to least squares when the ratio between errors on the independent and the dependent variables can be estimated. The relationship obtained is:
\end{abstract}

$$
M_{L}=1.164( \pm 0.011) * M_{D}-0.337( \pm 0.020)
$$

The new relationship allows to back-extend the local magnitude dataset to cover a period of about 15 years.

\section{Introduction}

Mt. Etna, in eastern Sicily, Italy, is a basaltic stratovolcano with persistent volcanic activity. It is located in a seismically active region astride the complex tectonic zone marking the boundary between the African and European plates [McKenzie 1970, Barberi et al. 1973, Lentini 1982, Montalto et al. 1996], where major regional structural lineaments play a key role in the dynamic processes of the volcano [Bonaccorso et al. 1996].

Volcano-tectonic earthquakes mainly occur at Mt. Etna in the form of swarms, whereas fore- main- aftershocks sequences are rarely recorded and seldom exceed magnitude 4.0 [e.g., Azzaro et al. 2011, Alparone et al. 2015]. The strongest historically recorded events, albeit of low magnitude ( $\leq 5.2$ according to CMTE [2014]), produced severe damage or even destruction in the epicentral area where the observed intensity reached up to IX-X EMS-98 [Grünthal 1998]. Most of the seismicity is located in the eastern flank of the volcano and is characterized by shallow volcano tectonic earthquakes with focal depth less than $7 \mathrm{~km}$ b.s.l. (Figure 1). It shows medium- to low-frequency seismic signals and complex signatures at stations just a few kilometers away from the epicentral area [Patanè and Giampiccolo 2004].

Earthquakes characterized by high frequency content and sharp arrivals, typical of tectonic areas, are instead mainly located below the volcano between 5 and $20 \mathrm{~km}$.

Despite the low values of magnitude, studies on seismicity are extremely important for the high seismic hazard given the strong effects observed in the epicentral areas; hence, the estimation of magnitude is a crucial parameter to be routinely measured with minimum uncertainty. Among the different ways of estimating magnitude, the Richter [1935] "local magnitude" $\left(\mathrm{M}_{\mathrm{L}}\right)$ represents a reference milestone because of its simple definition and widespread usage in different parts of the world [Gasperini 2002].

The local magnitude $\left(\mathrm{M}_{\mathrm{L}}\right)$ of an earthquake, as defined by Richter [1935], is the logarithm of half the peak-to-peak amplitude measured in microns, recorded by a Wood-Anderson seismograph at a distance of 100 $\mathrm{km}$ from the epicenter of that earthquake. The WoodAnderson (WA) is a standard torsion seismograph measuring a high-pass filtered displacement with a frequency domain response. A correction factor describes the variation of maximum amplitude taking into account the distance from source to receivers.

Since standard WA seismometers are often not available, local magnitudes are generally computed from amplitude recordings of other types of seismometers, digitally simulating a WA seismometer.

At Mt. Etna, seismic signal recordings have been available since the early 1990s, although at that time seismic stations were mostly equipped with vertical rather than horizontal seismometers, which are required by the Richter [1935] definition. Therefore, the earthquake magnitude at Mt. Etna has been estimated by the duration $\left(\mathrm{M}_{\mathrm{D}}\right)$ of the seismogram coda calibrated for 


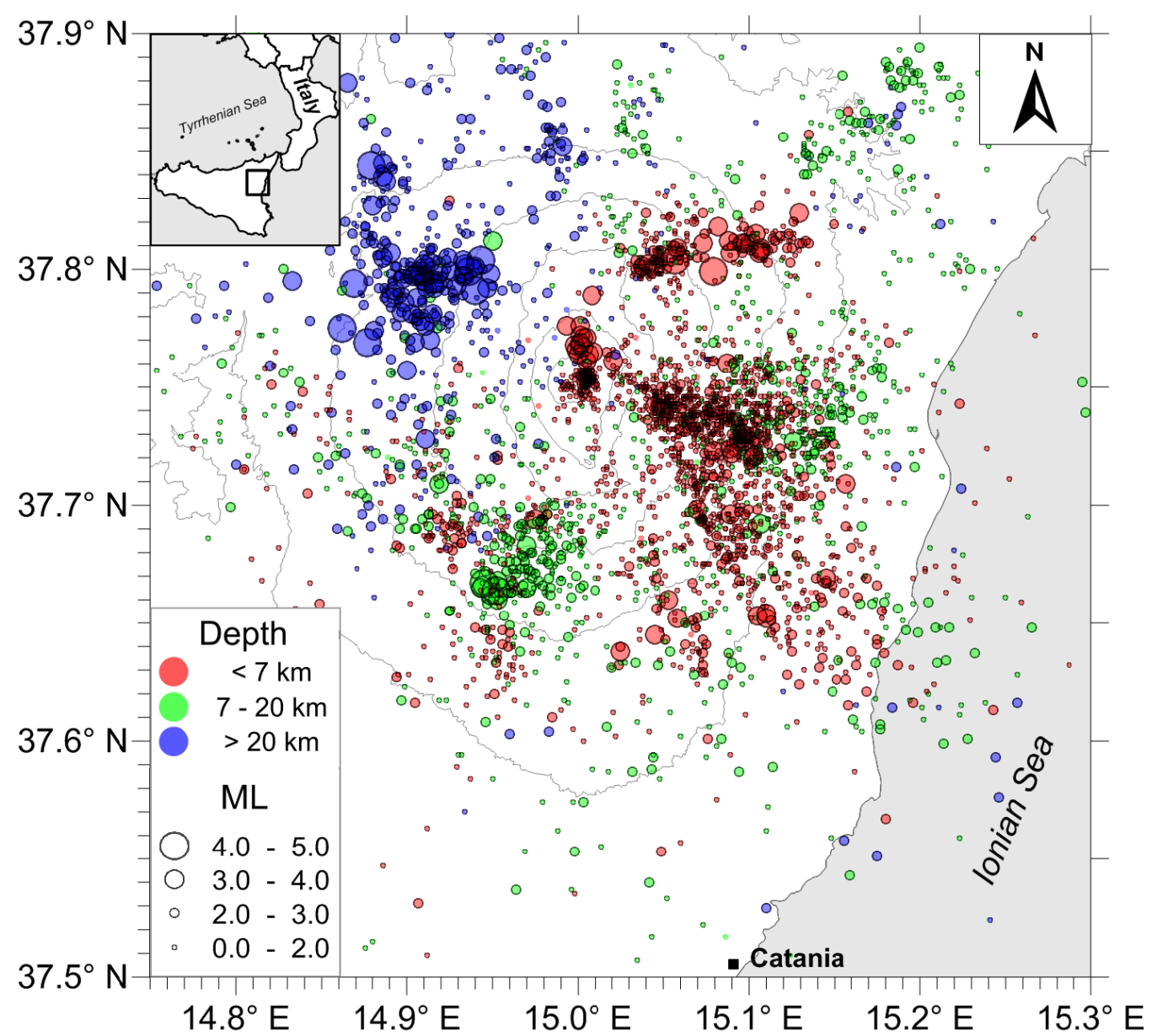

Figure 1. Map of Mt. Etna volcano and spatial distribution of the earthquakes used in this study.

Mt. Etna by the Caltabiano et al. [1986] relationship:

$$
\mathrm{M}_{\mathrm{D}}=-1.367+2.068 \log \tau+0.212 \log \Delta
$$

where $\tau$ is the duration time of the event in seconds and $\Delta$ is the hypocenter distance in $\mathrm{km}$ from the reference station.

The advantage of the above method is that the duration, defined as the time interval between the onset of the first pulse and the time when the amplitude of the seismogram coda decreases below the noise level, is influenced minimally by inaccuracies in the instrumental response function and the hypocentral location [Gasperini et al. 2013]. However, in volcanic areas the decay of the earthquake coda may be masked by the presence of noise, volcanic tremor or other shocks [Del Pezzo and Petrosino 2001, D’Amico and Maiolino 2005], so that calculation of the local magnitude, based on the less ambiguous signal amplitude, is desirable to estimate magnitude properly.

A first attempt to estimate the local magnitude $\mathrm{M}_{\mathrm{L}}$ was performed by D’Amico and Maiolino [2005], who used a dataset of 288 earthquakes, recorded by the Istituto Nazionale di Geofisica e Vulcanologia, Osservatorio Etneo (INGV-OE) during the 2002-2003 eruption, and the Lahr [1999] relationship:

$$
M_{L}=\log A+a \log \Delta-b
$$

where $\mathrm{A}$ is maximum half-amplitude of the horizontal component of the seismic recording, measured in $\mathrm{mm}$, and the term « $+a \log \Delta-b$ » takes the place of the term " $-\log \left(\mathrm{A}_{0}\right)$ » of Richter's [1935] relationship with $\mathrm{a}=0.15$, $\mathrm{b}=0.16$ for $\Delta<200 \mathrm{~km})$. Beginning in 2005, thanks to the improvement of the INGV-OE seismic network of Mt. Etna and the installation of digital stations equipped with broadband three-component sensors, local magnitude estimation became a routine procedure in monitoring the seismicity of the volcano. Today, $M_{L}$ is estimated as the mean value from several stations simulating a WA seismometer, as described in D'Amico and Maiolino [2005].

To ensure the continuity of a long dataset of coherent magnitude observations, the duration magnitude is still evaluated. Magnitude estimation in $M_{D}$ and $\mathrm{M}_{\mathrm{L}}$, though mutually related, do not produce the same results. For this reason, it is mandatory to adopt an empirical conversion to produce a homogeneous catalogue for the Mt. Etna region.

The use of earthquake data compiled at different 
times, subjected to different magnitude scales or from different networks, means dealing with the problem of magnitude homogeneity [e.g. Habermann 1991, Zùniga and Wyss 1995, Wiemer and Wyss 2000].

For reliable estimates of seismicity and hazard it is also necessary to make use of as much data as possible. In order to overcome this difficulty, many studies have relied on magnitude conversions based on linear regressions without regard for the time and method of the original observations on which they are based [Zùniga and Figueroa-Soto 2012].

For Mt. Etna volcano-tectonic earthquakes, some authors have proposed relationships between $M_{D}$ and $M_{L}$ through linear regression using selected datasets related to the large seismic sequences of 2001 and 2002-03 eruptions [D'Amico and Maiolino 2005, Giampiccolo et al. 2007], or using algorithms that take into account errors in both $\mathrm{M}_{\mathrm{D}}$ and $\mathrm{M}_{\mathrm{L}}$ with the same weight as in Murru et al. [2007].

The purpose of this study is to determine the $M_{D}-M_{L}$ relationship by applying the General Orthogonal Regression (GOR) [e.g. Carrol and Ruppert 1996] procedure, which has been widely used in the recent literature, to a dataset of $3921 \mathrm{M}_{\mathrm{L}}$ and $\mathrm{M}_{\mathrm{D}}$ available for earthquakes recorded at Mt. Etna from 2005 to 2014 [Gruppo analisi dati sismici 2015]. The relationship obtained is then used to produce a homogeneous magnitude for the whole Mt. Etna INGV-OE catalogue from 2000 to present, by calibrating the older $\mathrm{M}_{\mathrm{D}}$ with the more recent and reliable $M_{L}$.

\section{Instruments and dataset}

At Mt. Etna, spatial density and quality of the stations of the permanent seismic network run by INGVOE have been improved over time. In particular, starting from 2005, the technology of several stations has been upgraded from analogical short period 1-component to digital broadband 3-component. At present, the seismic monitoring network comprises about 50 stations, mainly equipped with broadband (40-second periods), 3-component, Nanometrics TRILLIUM seismometers and distributed all over the volcano.

The dataset used in this study consists of 3921 earthquakes (Figure 1) occurring from 2005 to 2014 and selected from the "Earthquakes catalogue of eastern Sicily and southern Calabria from 1999 to 2015" of INGVOE [Gruppo analisi dati sismici 2015]. Iterative linear earthquakes location was performed by using the HYPOELLIPSE algorithm [Lahr 1999] and the 1D crustal velocity model proposed for Mt. Etna area by Hirn et al. [1991]. Both duration and local magnitudes are available for the whole dataset. The accuracy of the $\mathrm{M}_{\mathrm{L}}$ estimates performed by INGV-OE, has been tested through

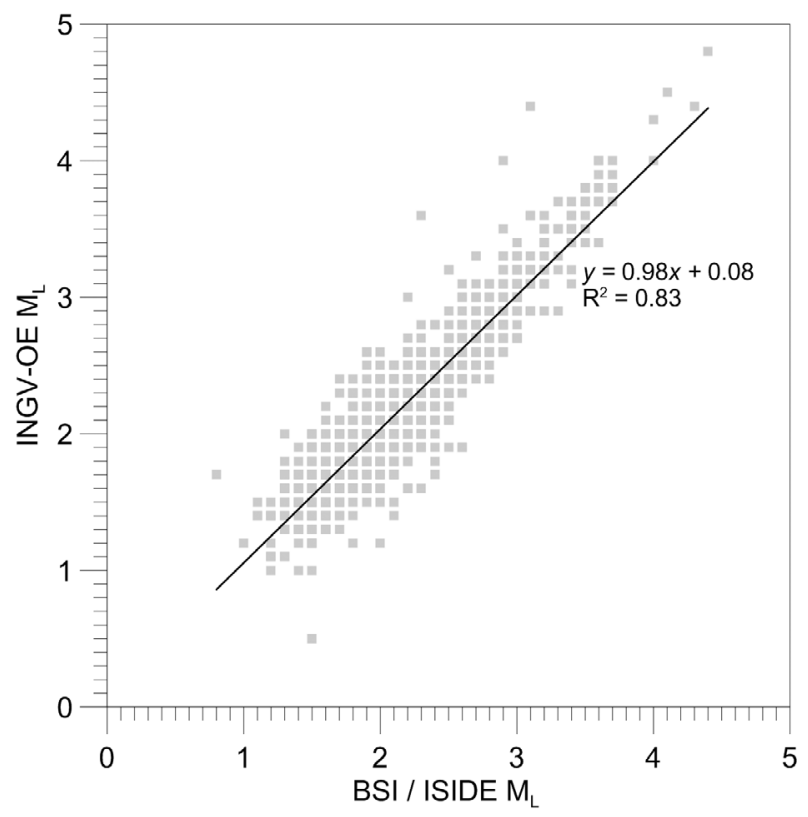

Figure 2. Plot of $M_{L}$ values of earthquakes occurring at Mt. Etna from 2005 to 2014 calculated by both local and national seismic network. $y$-coordinate data from Mt. Etna permanent seismic network [Gruppo analisi dati sismici 2015]; $x$-coordinate data from the Italian Seismic Bulletin [BSI 2012] and Italian Seismological Instrumental and Parametrical Database [ISIDE 2015].

the comparison with the $M_{L}$ estimates furnished, at national scale, by INGV seismic network in the "Italian Seismic Bulletin" [BSI 2012] and in the "Italian Seismic Instrumental and parametric Data-basE" [ISIDE 2015]. In Figure 2, the solid line represents the best-fit curve defining the relationship between the local magnitude computed with data from the two networks. Coefficients of the relationship show that $\mathrm{M}_{\mathrm{L}}$ values of INGV-

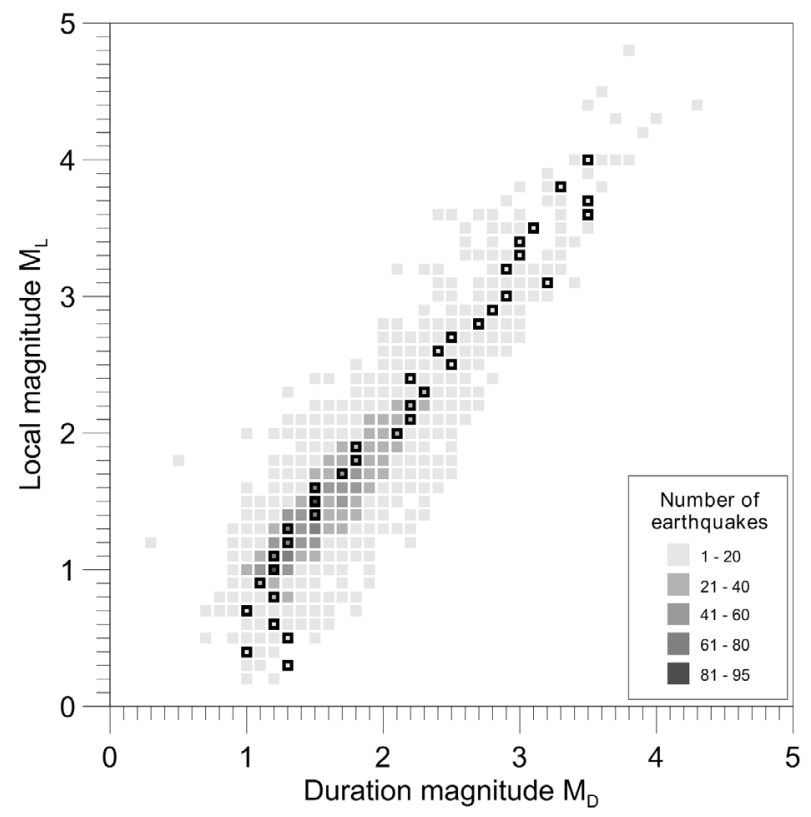

Figure 3. Plot of $M_{D}$ vs. $M_{L}$ values of the earthquakes occurring at Mt. Etna from 2005 to 2014. The grey scale indicates the number of earthquakes for each $M_{D}-M_{L}$ bins. Black squares indicate the $M_{D}$ value that occurs most often (mode) for each $\mathrm{M}_{\mathrm{L}}$ bin (0.1 unit). 
$\mathrm{OE}$ are in good agreement with those estimated using the national seismic network stations of INGV.

It is known in literature that a degree of bias is present when comparing $\mathrm{M}_{\mathrm{D}}$ vs. $\mathrm{M}_{\mathrm{L}}$ estimates [e.g. Gasperini 2002, D’Amico and Maiolino 2005, Castello et al. 2007]. In particular, for the our dataset $M_{D}$ values of small earthquakes are overestimated with respect to $M_{L}$ values and, conversely, they are underestimated for the strongest events. In Figure 3, the magnitude values are plotted in terms of density of number of couples of $M_{D}-M_{L}$, classified by grey scale. Mode of $M_{D}$ distribution for each $\mathrm{M}_{\mathrm{L}}$ bin (0.1 unit) is plotted with black squares. The plot shows a wide scatter of the data points that can be attributed to the uncertainties in the magnitude estimate. In fact, both duration and local magnitudes are calculated as the mean value from several stations. Moreover, in a volcanic area like Mt. Etna, where the noise is mainly related to the volcanic activity recorded by the instruments, uncertainties of coda duration have to be taken into account.

On the other hand, uncertainty in the estimate of the $M_{L}$ depends on the measurement of the maximum amplitude, which may be influenced by site effects due to soil amplification [Di Grazia et al. 2001].

The modes of $M_{D}$ distributions for each $M_{L}$ bin show a good linear trend for $\mathrm{M}_{\mathrm{L}}>1.0$. Below this threshold, the same $M_{D}$ value is calculated for several $M_{L}$ bins. In particular, earthquakes with $M_{L}<1.0$ are often estimated in $M_{D}$ as 1.1-1.2. Similar behavior may be observed for earthquakes with $\mathrm{M}_{\mathrm{L}}>3.0$ that are often estimated as $\mathrm{M}_{\mathrm{D}}=3.0$. Moreover, it is noteworthy that two strong earthquakes $\left(M_{L} \geq 4.5\right)$ had much smaller $\mathrm{M}_{\mathrm{D}}$ estimations.

Since duration magnitude estimation of smaller earthquakes appears to be unreliable, we removed 352 $M_{D}-M_{L}$ data having $M_{L}<1.0$ from the dataset used to calculate the GOR.

The absence of duration magnitudes outside the range 1.0-4.0 may clearly be observed also by computing the Gutenberg-Richter (G-R) frequency magnitude distribution of the catalogue shown in Figure 4A, for both duration and local magnitude. Small magnitude values are well-represented by $M_{L}$ but not by $M_{D}$. The distribution seems very similar from 1.0 to 3.0. In addition, the slope (b-value) of the cumulative curve is higher for $\mathrm{M}_{\mathrm{D}}$ than for $\mathrm{M}_{\mathrm{L}}$. This must be taken into account in carrying out studies using the b-value or seismicity rate, since it may have implications for both source processes and hazard estimation. Similarly, the cumulative plot of the seismic energy released in time (Figure 4B) enhances this $M_{D}-M_{L}$ behavior. The overall difference in terms of cumulative energy strain, released between that calculated in $\mathrm{M}_{\mathrm{D}}$ and that calculated in $\mathrm{M}_{\mathrm{L}}$ is $3.61 \times 10^{6} \mathrm{~J}^{0.5}$. Since the dataset is the same for both magnitudes, the observed difference has to be ascribed to the different estimation of the two magnitude scales, and it is particularly evident during the most powerful seismic sequences, such as those of May 2008 and December 2009.

\section{Regression analysis and results}

The Standard Linear Regression (SLR) is the simplest and most commonly used regression procedure applied in literature [e.g. Gasperini and Ferrari 2000, Gasperini 2002, Bindi et al. 2005, Braunmiller et al. 2005]. However, its application implies that error on the independent variable is negligible compared with the error on the dependent variable. Therefore, the use of SLR, without checking whether its basic requirements are satisfied, may lead to erroneous results [Castellaro et al. 2006]. Another approach is the Simple Orthogonal Regression (SOR), which assumes that both vari-
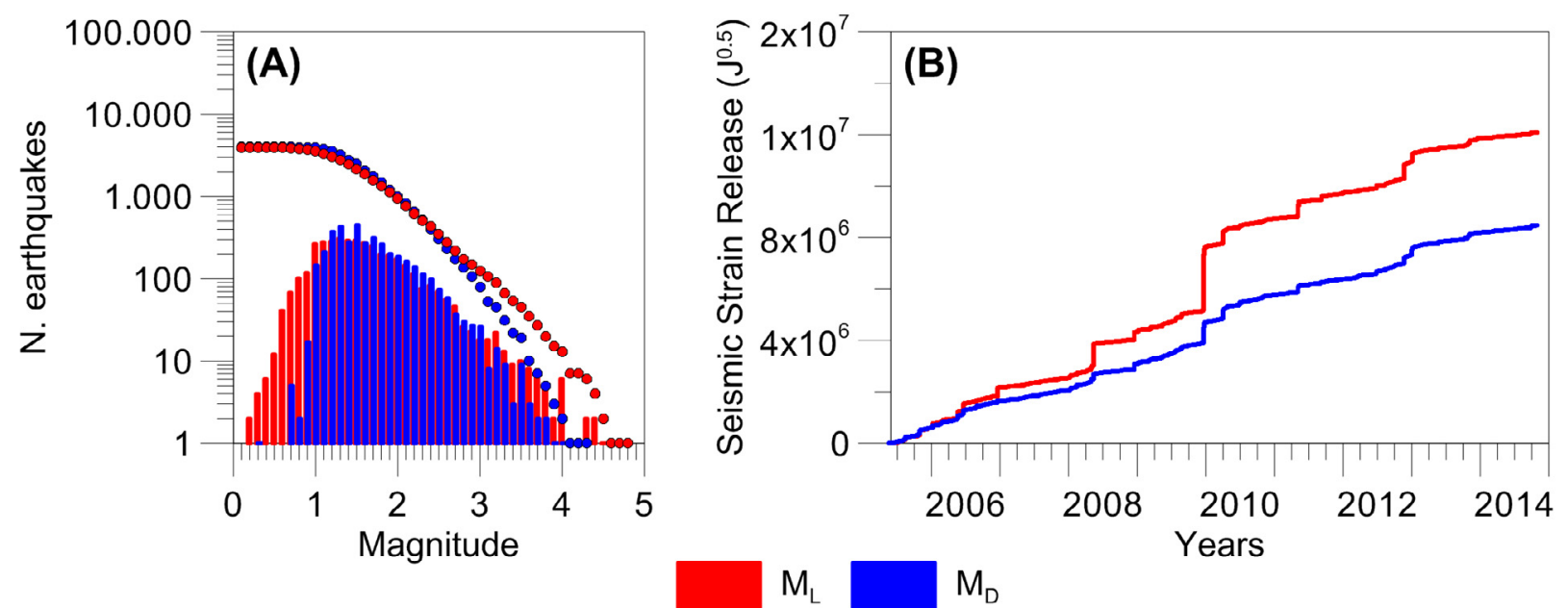

Figure 4. (A) Frequency magnitude distributions, in normal and cumulative scale, and (B) cumulative seismic strain release calculated using the Richter [1958] relationship for the earthquakes used in this study. Blue for $M_{D}$ dataset and red for $M_{L}$ dataset. 
ables have the same uncertainty [Ambraseys 1990, Gutdeutsch et al. 2002]. As the above conditions are not fully appropriate for magnitude data sets, the use of the General Orthogonal Regression (GOR), which is designed to account for the effects of measurement errors on both linearly related variables [Castellaro and Bormann 2007, Das et al. 2011], is generally preferable [Castellaro et al. 2006, Gasperini et al. 2013].

GOR basic procedure is described in detail in literature [Madansky 1959, Kendall and Stuart 1979, Fuller 1987, Carroll and Ruppert 1996, Castellaro et al. 2006, Das et al. 2011] and only a brief description of the main aspects involving magnitude is therefore given below.

The principle of GOR involves the minimization of

$$
\sum_{i=1}^{n}\left[\frac{\left(y_{i}-\alpha-\beta X_{i}\right)^{2}}{\eta}+\left(x_{i}-X_{i}\right)^{2}\right]
$$

in the unknowns $\alpha, \beta$ and $X_{i}$. Each measurement is sampled from a two-dimensional normal distribution centered at the value represented by the couple $\left(X_{i}, Y_{i}\right)$ and with major and minor axes equal to $\sigma_{x}$ and $\sigma_{y}$, which represents the standard deviation error of $x$ and $y$, respectively. The paths from the observed $\left(x_{i}, y_{i}\right)$ to the "true" $\left(X_{i}, Y_{i}\right)$ have slopes which depend on the errors affecting the two magnitudes. Equation (3) represents the weighted orthogonal distance when $\eta \neq 1$ and the squared Euclidean distance when $\eta=1$.

One drawback of the GOR application is that knowing the variance ratio

$$
\eta=\sigma_{\mathrm{ML}}^{2} / \sigma_{\mathrm{MD}}^{2}
$$

between the two variables $\left(\mathrm{M}_{\mathrm{D}}\right.$ and $\left.\mathrm{M}_{\mathrm{L}}\right)$ is mandatory. The variance $\left(\sigma^{2}\right)$ needs to be known for both magnitude scales. This requires that several independent estimations, based on data of different stations for the same earthquake, must be available.

When the square root of the error variance ratio $\eta$ is in the range between 0.7 and 1.8, GOR relation is qualitatively better than SLR relation [e.g. Castellaro and Bormann 2007].

To perform the regression analyses, a great deal of effort was made to assess the magnitude uncertainties that are required for the application of the GOR method. The local magnitude, for each earthquake in the catalogue, is calculated as the average generally by using a number of stations between 5 and 18. The standard deviation for each $M_{L}$ value is known. For the whole dataset, the standard deviation of the estimated magnitudes ranges between 0.14 and 0.67 , with average $\sigma_{\mathrm{ML}}=0.27$. Conversely, notwithstanding that the duration magnitude is estimated as an average value, no in-

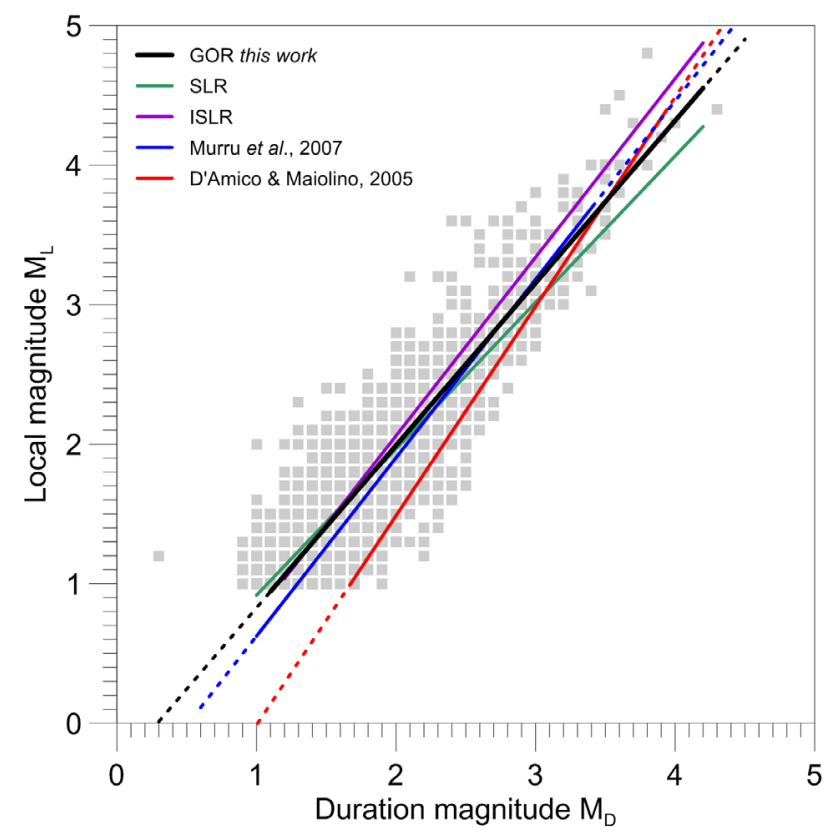

Figure 5. Plot of the obtained GOR relationship between $M_{L}$ and $M_{D}$ (black line). Grey boxes indicate $M_{D}-M_{L}$ couples. For comparison, SLR, ISR, Murru et al. [2007] and D'Amico and Maiolino [2005], are also plotted. Dashed lines indicate data outside the range of definition of the relationships.

formation about its uncertainty is known. To overcome this problem and obtain a reliable value of uncertainty on the estimation, for a subset of 210 events the duration of the seismogram coda was re-estimated for all available recording stations (generally from 2 to 12).

We were thus able to estimate mean $\mathrm{M}_{\mathrm{D}}$ and its standard deviation $\sigma$ for each of the 210 events. For this subset of events, $\sigma$ of the estimated magnitudes ranges between 0.11 and 0.64 with average $\sigma_{\mathrm{MD}}=0.22$. Given that neither the procedure to measure the coda duration nor the seismic instruments used have changed since 2005, we may assume that this subset is representative of the whole dataset.

Since the square root of $\eta=1.23$, we are confident that the application of GOR gives better results than SLR [Castellaro and Bormann 2007].

The GOR relationship obtained is:

$$
\mathrm{M}_{\mathrm{L}}=1.164( \pm 0.011) * \mathrm{M}_{\mathrm{D}}-0.337( \pm 0.020)
$$

where the rms between calculated $\mathrm{M}_{\mathrm{L}}$ and observed $\mathrm{M}_{\mathrm{L}}$ is 0.25 . The relationship (Figure 5 , black line) is in good agreement with the trend of the mode of the distribution of $M_{D}$ per $M_{L}$ bins (see Figure 3). Dashed segments indicate the magnitude values outside the range used for the regression. Figure 5 also shows SLR, inverse-SR (ISR) and other relations known in literature [Murru et al. 2007, D’Amico and Maiolino 2005]. In particular, the Murru et al. [2007] relationship, although similar to GOR, calculates smaller values of magnitude 


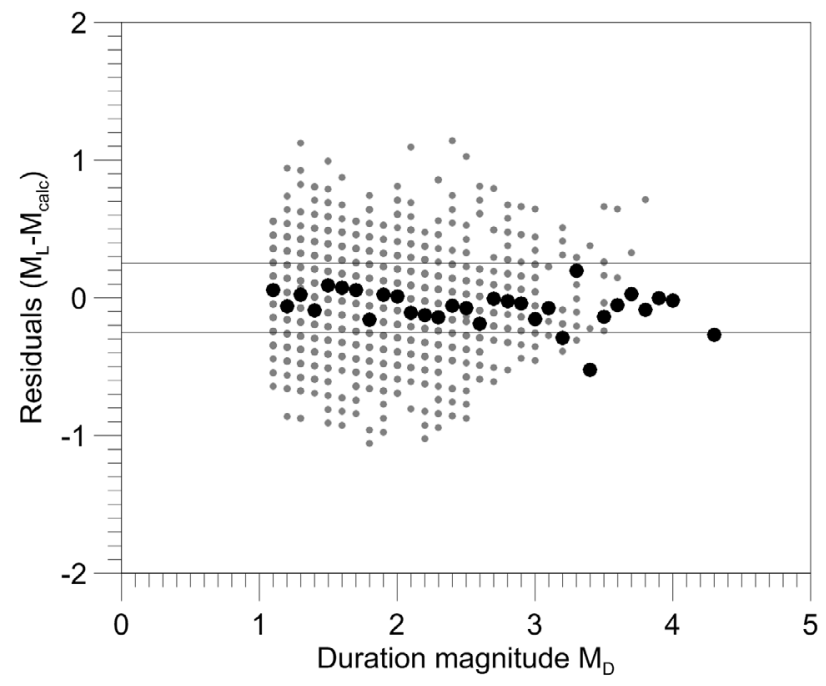

Figure 6. Residuals between observed $M_{L}$ and calculated $M_{L}$ with respect to observed $M_{D}$. Thin horizontal lines indicate the standard error threshold of the $M_{D}-M_{L}$ relationship.

(0.2 unit difference for $M_{D}=1.0$ ) for the less powerful events. Conversely, SLR and ISR show good agreement only for small earthquakes.

To verify the goodness of the new relation, a t-test was performed between the observed $\mathrm{M}_{\mathrm{L}}$ and calculated $\mathrm{M}_{\mathrm{L}}$ by GOR. In particular, the null hypothesis that the means of the two populations are equal has been tested. The test indicates that there is a probability lower than $6.48 \%$ that the observed and calculated magnitude are different.

In Figure 6 the difference between observed and calculated $M_{L}$ versus $M_{D}$ is plotted; black circles indicate the most frequent values for each $M_{D}$ bin. They fall within the range defined by the standard error of the relationship ( \pm 0.25 ) for $M_{D}$ values between 1.0 and 3.2, although there is some disagreement over such range.

\section{Conclusions}

For seismological applications, including homogenization of earthquake catalogues, it is important to know how different magnitude determinations compare as well as the associated measurement errors. Mt. Etna catalogue covers earthquakes occurring in the area since the 90 s and, as in most cases, changes in instrumentation and the network involved in the monitoring, may have introduced changes in magnitude with time.

In this study, a new relation to convert $\mathrm{M}_{\mathrm{D}}$ magnitude to $\mathrm{M}_{\mathrm{L}}$ of $\mathrm{Mt}$. Etna earthquakes has been derived using a dataset of earthquakes recorded in the period 2005-2014 and applying the most commonly used GOR approach.

A retrospective analysis of the cumulative energy strain release of the last 14 years (Figure 7), calculated by $M_{L}$ (observed or estimated, red line), shows that, overall, the energy strain release is increased by about $1 \times 10^{7}$ units with respect to the estimated $M_{D}$ (blue line). This behavior is particularly noticeable during the seismic crisis of 2001 and 2002 related to the volcanic eruptions and it is coherent with that observed in 2008 and in 2009 (see also Figure 4B for a detailed magnification of this time span). The grey areas in background indicate when a calculated $\mathrm{M}_{\mathrm{L}}$ was used.

The calibration of various magnitude data sets described above has been used to build a homogenized catalogue in $\mathrm{M}_{\mathrm{L}}$ from 2005 to 2014 .

The new relationship is an effective way to back extend the more reliable local magnitude to the whole Mt. Etna catalogue and allows obtaining a homogeneous dataset of magnitudes.

Moreover, taking into account that $\mathrm{M}_{\mathrm{L}}$ calculated with the seismic stations of the Mt. Etna permanent

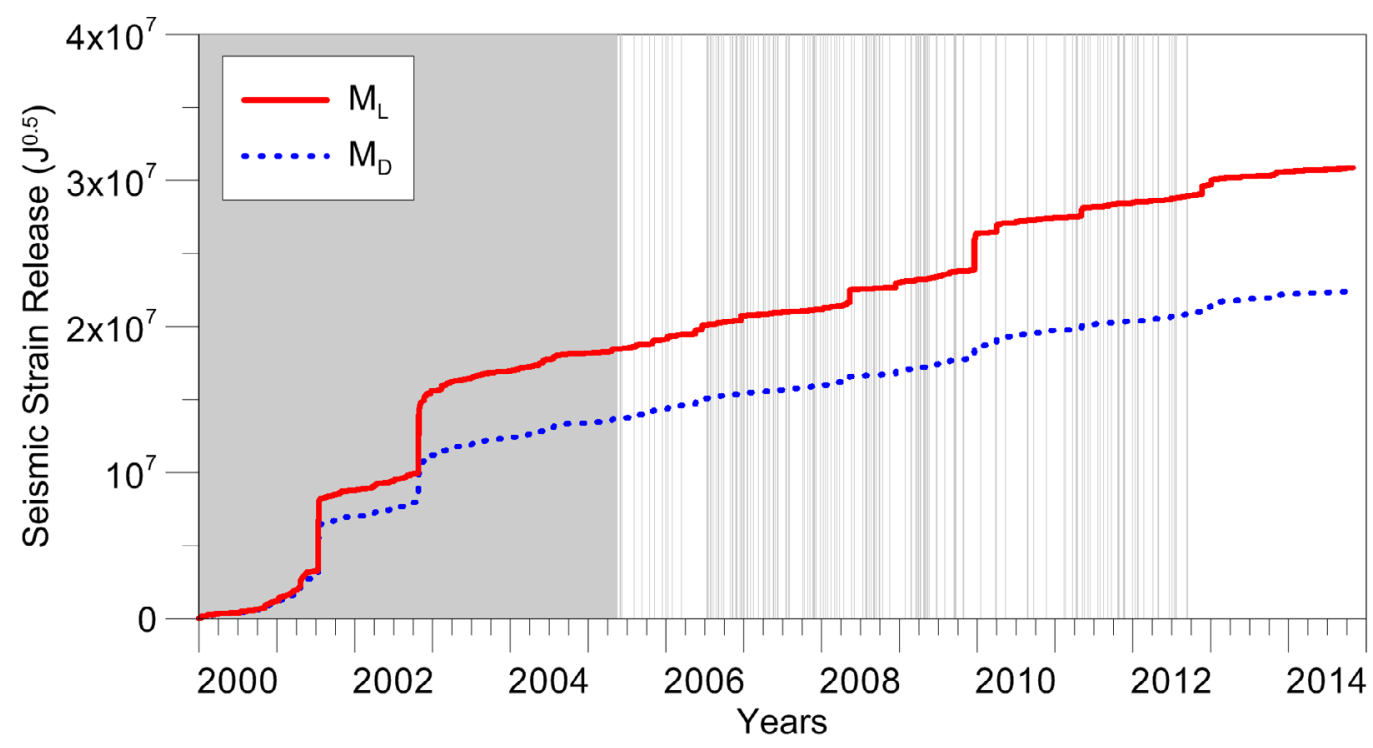

Figure 7. Cumulative seismic strain release of Mt. Etna volcano from 2000 to 2014 calculated using the Richter [1958] relationship. Dotted blue line for $M_{D}$ dataset and red line for observed or calculated $M_{L}$ dataset. Grey areas indicate when a calculated $M_{L}$ was used. 
network are in good agreement with those calculated by the national seismic network (Figure 2), the relationship may be used to integrate INGV-OE data with those of different networks.

\section{References}

Alparone, S., V. Maiolino, A. Mostaccio, A. Scaltrito, A. Ursino, G. Barberi, S. D’Amico, G. Di Grazia, E. Giampiccolo, C. Musumeci, L. Scarfi and L. Zuccarello (2015). Instrumental seismic catalogue of Mt. Etna earthquakes (Sicily, Italy): ten years (2000-2010) of instrumental recordings, Annals of Geophysics, 58,4, 1-11.

Ambraseys, N.N. (1990). Uniform magnitude reevaluation of European earthquakes associated with strongmotion recordings, Earthq. Eng. and Struct. Dyn., 19, 1-20.

Azzaro, R., S. D'Amico and T. Tuvè (2011). Estimating the magnitude of historic earthquakes from macroseismic intensity data: new relationships for the volcanic region of Mount Etna (Italy), Seismol. Res. Lett., 82 (4), 533-544.

Barberi, F., P. Gasparini, F. Innocenti and L. Villari (1973). Volcanism of the Southern Tyrrhenian Sea and its geodynamic implications, J. Geophys. Res., 78 (23), 5221-5232.

Bindi, D., D. Spallarossa, C. Eva and M. Cattaneo (2005). Local and duration magnitude in northwestern Italy and seismic moment versus magnitude relationships, B. Seismol. Soc. Am., 95 (2), 592-604.

Bonaccorso, A., F. Ferrucci, D. Patanè and L. Villari (1996). Fast deformation processes and eruptive activity at Mt. Etna (Italy), J. Geophys. Res., 101 (B8), 17467-17480.

Braunmiller, J., N. Deichmann, D. Giardini, S. Wiemer and the SED Magnitude Working Group (2005). Homogeneous moment-magnitude calibration in Switzerland, B. Seismol. Soc. Am., 95 (1), 58-74.

BSI (2012). Bollettino Sismico Italiano / Italian Seismic Bulletin, Istituto Nazionale di Geofisica e Vulcanologia, Rome; http:/ / bollettinosismico.rm.ingvit/.

Caltabiano, T., D. Condarelli, S. Gresta and D. Patanè (1986). Analisi preliminare dei dati della stazione sismica di Serra Pizzuta Calvarina, CNR IIV Open File Rep., $10 / 86$.

Carroll, R.J., and D. Ruppert (1996). The use and misuse of orthogonal regression in linear errors-in-variables models, American Statistician, 50 (1), 1-6.

Castellaro, S., F. Mulargia and Y.Y. Kagan (2006). Regression problems for magnitudes, Geophys. J. Int., 165, 913-930.

Castellaro, S., and P. Bormann (2007). Performance of Different Regression Procedures on the Magnitude
Conversion Problem, B. Seismol. Soc. Am., 97, 1167-1175.

Castello, B., M. Olivieri and G. Selvaggi (2007). Local and duration magnitude determination for the Italian Earthquake Catalog, 1981-2002, B. Seismol. Soc. Am., 97, 128-139.

CMTE Working Group (2014). Catalogo Macrosismico dei Terremoti Etnei, 1832-2013, Istituto Nazionale di Geofisica e Vulcanologia, Catania; http: / / www. ct.ingvi.it/macro/.

D'Amico, S., and V. Maiolino (2005). Local magnitude estimate at Mt. Etna, Annals of Geophysics, 48 (2), 215-229.

Das, R., H.R. Wason and M.L. Sharma (2011). Global regression relations for conversion of surface wave and body wave magnitudes to moment magnitude, Nat. Hazards, 59, 801-810.

Del Pezzo, E., and S. Petrosino (2001). A local-magnitude scale for Mt. Vesuvius from synthetic WoodAnderson seismograms, J. Seismol., 5, 207-215.

Di Grazia, G., H. Langer, A. Ursino, L. Scarfi and S. Gresta (2001). On the estimate of earthquake magnitude at a local seismic network, Annals of Geophysics, 44 (3), 579-591

Fuller, W.A. (1987). Measurement Error Models, John Wiley, New York.

Gasperini, P., and G. Ferrari (2000). Deriving numerical estimates from descriptive information: The computation of earthquake parameters, Annals of Geophysics, 43 (4), 729-746.

Gasperini, P. (2002). Local magnitude revaluation for recent Italian earthquakes (1981-1996), J. Seismol., 6, 503-524.

Gasperini, P., B. Lolli and G. Vannucci (2013). Empirical Calibration of Local Magnitude Data Sets Versus Moment Magnitude in Italy, B. Seismol. Soc. Am., 103, 2227-2246.

Giampiccolo, E., S. D’Amico, D. Patanè and S. Gresta (2007). Attenuation and source parameters of shallow microearthquakes at Mt. Etna volcano (Italy), B. Seismol. Soc. Am., 97 (1b), 184-197.

Grünthal, G. (1998). European Macroseismic Scale 1998 (EMS-98), European Seismological Commission, subcommission on Engineering Seismology, Working Group Macroseismic Scales, Conseil de l'Europe, Cahiers du Centre Européen de Géodynamique et de Séismologie, 15, Luxembourg, p. 99; http://ww w.ecgs.lu/cahiers-bleus/.

Gruppo analisi dati sismici (2015). Catalogo dei terremoti della Sicilia Orientale - Calabria Meridionale, Istituto Nazionale di Geofisica e Vulcanologia, Catania; http:/ / www.ct.ingv.it/ufs/analisti/ catalogolist. php. 
Gutdeutsch, R., D. Kaiser and G. Jentzsch (2002). Estimation of earthquake magnitudes from epicentral intensities and other focal parameters in Central and Southern Europe, Geophys. J. Int., 151 (3), 824-834.

Habermann, R.E. (1991). Seismicity rate variations and systematic changes in magnitudes in teleseismic catalogs, Tectonophysics, 193, 277-289.

Hirn, A., A. Nercessian, M. Sapin, F. Ferrucci and G. Wittlinger (1991). Seismic heterogeneity of Mt. Etna: structure and activity, Geophys. J. Int., 105, 139-153.

ISIDE (2015). Italian Seismological Instrumental and Parametric Data-basE, Istituto Nazionale di Geofisica e Vulcanologia, Rome; http: / / iside.rm.ingv. it/iside/standard/index.jsp.

Kendall, M., and A. Stuart (1979). The Advanced Theory of Statistics, vol. 2, Charles Griffin, London.

Lahr, J.C. (1999). Hypoellipse: a computer program for determining local earthquake hypocentral parameters, magnitude, and first motion pattern (Y2K compliant), U.S. Geol. Survey Open File Rep., 99-23.

Lentini, F. (1982). The geology of the Mt. Etna basement, Mem. Soc. Geol. It., 23, 7-25.

Madansky, A. (1959). The fitting of straight lines when both variables are subject to error, J. Am. Stat. Assoc., 54, 173-205.

McKenzie, D. (1970). Plate tectonics of the Mediterranean region, Nature, 226, 239-243.

Montalto, A., S. Vinciguerra, S. Menza and G. Patanè (1996). Recent Seismicity of Mount Etna: Implication for Flank Instability, In: W.J. McGuire, A.P. Jones and J. Neuberg (eds.), Volcano instability on the Earth and other planets: Geological Society of London, Special Publications, 110, 169-177.

Murru, M., R., Console, G. Falcone, C. Montuori and T. Sgroi (2007). Spatial mapping of the $b$ value at Mount Etna, Italy, using earthquake data recorded from 1999 to 2005, J. Geophys. Res., 112, B12303; doi:10.1029/2006JB004791.

Patanè, D., and E. Giampiccolo (2004). Faulting processes and earthquake source parameters at Mount Etna: state of art and perspective, In: A. Bonaccorso, S. Calvari, M. Coltelli, C. Del Negro and S. Falsaperla (eds.), Mt. Etna: Volcano Laboratory, American Geophysical Union, 143, 167-189.

Richter, C. F. (1935). An instrumental earthquake magnitude scale, B. Seismol. Soc. Am., 25 (1), 1-32.

Richter, C.F. (1958). Elementary Seismology, W.H. Freeman and Co., San Francisco.

Wiemer, S., and M. Wyss (2000). Minimum magnitude of completeness in earthquake catalogs: Examples from Alaska, the western US and Japan, B. Seismol. Soc. Am., 90, 859-869.

Zùniga, F.R., and M. Wyss (1995). Inadvertent changes in magnitude reported in earthquake catalogs: influence on b-value estimates, B. Seismol. Soc. Am., 85 (6), 1858-1866.

Zùniga, F.R., and A. Figueroa-Soto (2012). Converting Magnitudes Based on the Temporal Stability of aand b-Values in the Gutenberg-Richter Law, B. Seismol. Soc. Am., 102 (5), 2116-2127.
${ }^{\star}$ Corresponding author: Tiziana Tuvè, Istituto Nazionale di Geofisica e Vulcanologia, Sezione di Catania, Osservatorio Etneo, Catania, Italy; email: tiziana.tuve@ingv.it.

C 2015 by the Istituto Nazionale di Geofisica e Vulcanologia. All rights reserved. 